\section{Pasteur Institute in AIDS fracas}

ACQUIRED immune deficiency syndrome - AIDS - is raising strong emotions in France, particularly at the Institut Pasteur in Paris. The institute is still perhaps the most prestigious institution in French biology, so there was strong reaction there to the newspaper headline "Institut Pasteur, sick with gay cancer' (Libération, 27 June). The supposed problem was not with the research institute itself, but with its independent commercial offshoot, Institut Pasteur Production (IPP) which was accused of clandestine importation of American blood plasma (automatically suspected of AIDS contamination) to help with manufacture of hepatitis $B$ vaccine. A chimpanzee was also said to have died in testing the first batch of such vaccine: it was an apparent scandal.

So last week the Institut Pasteur proper came to the aid of its offspring, while still keeping a little distance from it. François Jacob, Nobel prize-winner and doyen of the Institut Pasteur, described the Libération headline as "scandal-mongering". Liberation should also have distinguished between the Institut Pasteur and IPP, he said. (The institute has a 45 per cent shareholding, but little influence over IPP.) And in an official press statement, it was said that "The Institut Pasteur is used to criticism. But cannot accept slander.'"

IPP is itself about to sue Liberation for FF1 million for defamation and for possible loss of business in a fierce competition with its American rival, Merck Sharp and Dohme. Both companies are seeking lucrative contracts in Asia, and particularly in China where IPP had foreseen a market of "dozens of millions of doses of vaccine", and order of magnitude larger than its present sales. IPP expected the vaccine soon to become its major product. However, IPP's market position may have been compromised by the press attacks, IPP research director M. Prunet said on Friday.

As for some of Liberation's accusations, the truth now seems a little difficult to establish since French Health officials who earlier were said to have been "furious" about not having been informed by IPP about the use of American plasma now have to accept a Ministry of Health statement that the ministry was, in fact, informed, and had granted authorization from the first date of importation in March 1982. It must be remembered, said Dr Jacques Netter, responsible for the National Health Laboratory which monitors testing of the IPP vaccine, that when the authorization was given, AIDS was not so important. The real question is whether the vaccine is good and safe, and it is.

On other matters, things are clearer. The chimpanzee was one of a colony treated with vaccine, on which a liver biopsy is done each month. In this particular healthy chimpanzee, treated with the first lot of vaccine to be based in part on American plasma ( 3 per cent of the total), there was a small lesion of the liver. Two French and one American expert concluded it was "nonspecific" and the vaccine was marketed (some to West Germany) with the approval of the French Ministry of Health, says M. Prunet of IPP. However, there had been "some disagreement"' (says Dr Netter) among the experts about the nature of the lesion. When a kit for detecting human T-cell leukaemia virus (HTLV) - a suspected AIDS agent - arrived from the United States, the ministry requested a new test. Marketing was stopped for a while but the test proved negative and sales were resumed.

Moreover, IPP's production process seems to be thoroughly safe, at least in the elimination of known infectious agents. In tests, viruses such as polio introduced deliberately into the initial plasma are reduced by factors of $10^{20}$ by centri-
THE outlook seems stormy for next week's annual meeting of the International Whaling Commission (IWC) in the English south-coast town of Brighton. Delegates from Norway, in particular, are steeling themselves for a difficult time. And at the back of everyone's mind is the question of what is likely to happen to last year's resolution that zero catch quotas should be imposed for all commercial whaling from the end of 1985 .

After that resolution was passed last year, four countries (Japan, Norway, Peru and the Soviet Union) lodged formal objections and so are not bound by it. Japan considered pulling out of IWC altogether, but has not yet done so. IWC itself is powerless to enforce the resolution, so it will be up to individual countries to provide the teeth. Only the United States is bound to impose sanctions, but they will not be used until the resolution is actually infringed.

Norway's problems concern stocks of Minke whales in the North Atlantic. Last year the commission was unable to agree on a catch quota, but Norway diplomatically adopted a figure of 1,690 . New evidence from IWC's scientific committee suggests that stocks are substantially lower than the Norwegians assumed, so there will be strong pressure this year for a very much smaller quota.

Minke whales are also taken in the Antarctic, by Japan and the Soviet Union. Last year a quota of 7,072 was agreed, based on estimates of stocks extrapolated from visual sightings. The sightings, however, are made only in a small part of the Minke's range, and the scientific com- fugation and chemical treatment (ending with formaldehyde), M. Prunet claims. Formaldehyde "denatures"' nucleic acid, he says. Another, enzymatic test, detects reverse transcriptase, the signal for retroviruses (like HTLV). So if AIDS is due to a virus with properties biologists understand, the IPP process eliminates it, Prunet says. If it is not, he has "no answer"'. But no case of AIDS has yet resulted from IPP's use of the vaccine on over $10,000 \mathrm{pa}$ tients, and a follow-up study with the similar Merck vaccine in the United States has shown it causes no incidence of AIDS in low AIDS-risk patients and no significant change (in fact, a slight decrease) in high risk patients.

Liberation is left with one substantial point: that confusion over the origin of IPP's plasma, and an early lack of information about the chimpanzee, which resulted in the facts being "discovered" by journalists, indicate a lack of "clarity" in IPP's affairs; and that it would have been much better for the company if the confusion had not been allowed to arise. IPP might heartily agree.

Robert Walgate

\title{
Norway this year's villain?
}

mittee's evidence this year includes a strong criticism of the extrapolation procedure; some scientists believe it significantly overestimates whale stocks.

There is likely to be another big argument over stocks of Bryde's whale off the coast of Peru. Peruvian delegates will be in an embarrassing position: last year they unilaterally increased their catch quotas but then failed to catch anything approaching the figure. El Nino, the South Pacific current that has been behaving oddly this year, may be used to provide an explanation. The Peruvians can in any case expect

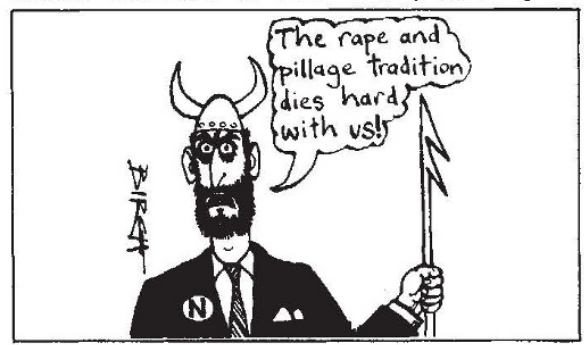

full support from the Japanese delegation, since Peru's whaling effort is in large part run by Japan. This, together with Japanese proposals to build a whaling station in the Philippines, should ensure that Japan is not kept entirely out of the spotlight.

Subsistence whaling by Eskimos in Alaska has been the subject of much attention. Last year a quota of 45 Bowhead whales over three years was agreed, but US officials have been under severe pressure to increase this total. At this year's Brighton meeting, the United States will try to increase the quota but scientists are arguing for a total ban on catches of the Bowhead. 